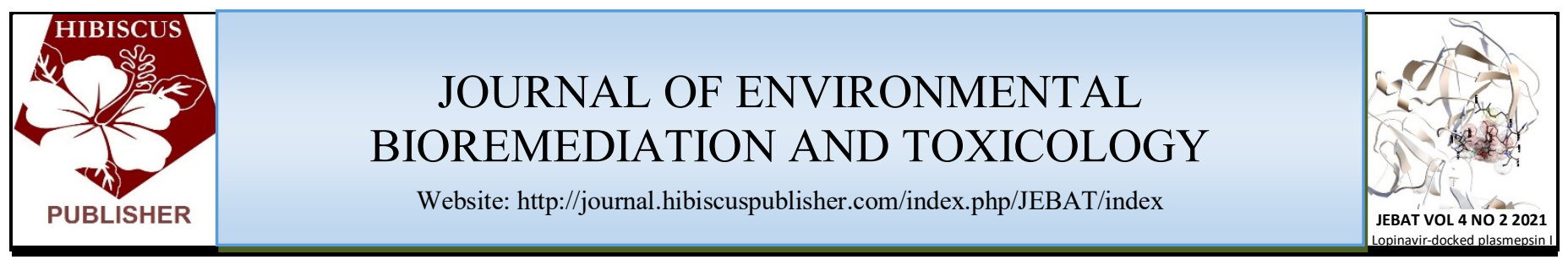

\title{
Histological and Weight Changes in the Testes of Plasmodium Berghei- Infected Swiss Mice Treated with Chloroquine
}

\author{
Etukudoh N.S. ${ }^{1}$, Deko A.B. ${ }^{2}$, Obeta M.U. ${ }^{3 *}$, Oyero S.K. ${ }^{4}$, Ejinaka O.R. ${ }^{5}$ and I.E. Ibanga ${ }^{3}$ \\ ${ }^{1}$ Department of Haematology, Federal School of Medical Laboratory Science, Npkwuis 930105, Jos, Nigeria. \\ ${ }^{2}$ Department of Histopathology, Federal School of Medical Laboratory Science, Npkwuis 930105, Jos, Nigeria. \\ ${ }^{3}$ Department of Chemical Pathology, Federal School of Medical Laboratory Science, Npkwuis 930105, Jos, Nigeria. \\ ${ }^{4}$ Department of Histopathology, Jos University Teaching Hospital, Npkwuis 930105, Jos, Nigeria. \\ ${ }^{5}$ Department of Parasitology, Federal School of Medical Laboratory Science, Npkwuis 930105, Jos, Nigeria. \\ *Corresponding author: \\ Uchejeso Obeta, \\ Federal School of Medical Laboratory Science, \\ Npkwuis 930105, \\ Jos, \\ Nigeria. \\ Email: uchejesoobeta@gmail.com
}

\section{HISTORY}

Received: $15^{\text {th }}$ Oct 2021

Received in revised form: $24^{\text {th }}$ Nov 2021 Accepted: $20^{\text {th }}$ Dec 2021

\section{KEYWORDS \\ Plasmodium berghei \\ Chloroquine \\ Malaria \\ Malaria \\ Histomorphology}

\begin{abstract}
Chloroquine has gained great emphasis in the treatment of malaria. This study sought experimentally to determine the histomorphological and weight changes in the testes of male mice infected with Plasmodium berghei and treated with chloroquine. The study used 30 Swiss mice divided into five groups. Group 1 is Control that was not infected with Plasmodium berghei and not treated with chloroquine as control, Group 2 is Plasmodium (Plasmodiul berghei) Infected animals but not treated, Group 3 is Plasmodium Infected animals + Chloroquine $(5 \mathrm{mg} / \mathrm{kg})$, Group 4 is Plasmodium Infected animals + Chloroquine $(10 \mathrm{mg} / \mathrm{kg})$ and Group 5 is Plasmodium Infected animals + Chloroquine $(15 \mathrm{mg} / \mathrm{kg})$. The mice were treated for 7 days after parasitaemia was confirmed and the Group 2-5 testes studied with reference to Group 1. The results showed that the Group 2 showed a little distortion, difference in spermatogenic activities and increased cellular activities; Group 3 showed large, convoluted tubules, moderate number of spermatids and large interstitial spaces, Group 4 showed Large seminiferous tubules, large spermatids, increased distortion and group 5 showed shrinking of seminiferous tubules, degeneration of interstitial cells of Leydig cells and Sertolic cells with spermatids. Groups 1-5 showed no significant effect in in body weights and testes weights of Swiss mice. Plasmodium berghei (malaria) and chloroquine have effects on histomorphological structures of Swiss mice testes but not on their teste's weights. The testicular section from Swiss mice infected with malaria and treated at various doses when compared with the Control (Group 1) showed some moderate distortion in some structures like seminiferous tubules, connective tissues between the tubules, lumen and interstitial spaces. It can be deducted that Plasmodium berghei which caused parasitaemia in mice could cause a little tissue effect on mice if not treated.
\end{abstract}

\section{INTRODUCTION}

In Africa and Nigeria in particular, malaria is endemic and there has been evolution of malaria therapy over the years due to drug resistance. Chloroquine is a synthetic derivative of 4aminoquinoline, in spite of reported cases of chloroquine side effects, it has been used for the control (prophylaxis) and treatment of malaria [1]. Chloroquine is one of the oldest drugs used in the treatment of malaria. Plowe [2] while discussing antimalarial resistance in Africa showed that chloroquine was one of the most important and successful drugs ever used against falciparum malaria because of its low cost, low toxicity and high efficacy against susceptible parasites, but had actually failed in Africa. Apart from anti-malaria activity, chloroquine is useful in the treatment of gastrointestinal ameobiasis systemic lupus erythematosis, fluke infection, discoid lupus erythematosis and rheumatoid arthritis [3].

Plasmodium species are a group of parasites that affect mostly the red cells. Malaria parasitaemia has been reported to adversely affect male reproductive functions by decreasing sperm count, sperm viability as well as serum testosterone concentration $[4,5]$. Plasmodium berghei is a unicellular parasite (protozoan) which infects mammals other than human. It is used 
in many research institutes for animal experimental studies on malaria. Considering that malaria has been managed with chloroquine and chloroquine related products like hydroxychloroquine in Africa and other parts of the world, this study can be justified to find of the effect of chloroquine on testes of mice when infected with malaria and when treated with chloroquine towards enhancing knowledge base on the testes morphology and weight considering the relationship between laboratory animal and humans [6].

Ashiru et al. [7] in histological observation, reported irregular seminiferous tubules as well as immature spermatozoa in the lumen of seminiferous tubules of chloroquine phosphatetreated animals. Russel et al. [8] also reported necrotic testicular lesion after chloroquine treatment. Asuquo et al. [9] reported shrunken seminiferous tubules, degeneration of interstitial tissue and loss of interstitial cells of Leydig. Desai et al. [10] agreed that chloroquine induced toxicity in Swiss mice because of several aberrations in sperm parameters. Ekaluo et al. [11] reported that chloroquine decreased weight of testis. Notably, when mice testes are affected, the mice reproductive system is also affected, thus there can be low sperm count, mutation of the gene, and infertility though some can be reversible [12]. This study was aimed at investigating histological and weight changes in the testes of Plasmodium berghei-infected mice treated with chloroquine. The study is set to measure the extent to which malaria affects the reproductive and other functions of mice.

\section{MATERIALS AND METHODS}

\section{Experimental Animals}

The study was approved by the Ethical Committee of the Federal School of Medical Laboratory Technology, Jos via the letter (Ref. No.: EC/FSMLT/021/2018) on 3rd September 2018.

Thirty male Swiss mice (aged 8 months) weighing between $15-$ $30 \mathrm{~g}$ were used for the present study. The animals were obtained from National Veterinary Research Institute Vom Jos, Nigeria. Animals were kept in the Animal House of the Federal School of Medical Laboratory Technology, Jos where they were acclimatized for one week under favourable laboratory conditions before the study. They were housed in groups of 10 mice per cage on the bed of sterilized iron cage and wire mesh top measuring 15.5 by $10 \mathrm{~cm}$. They were fed ad-libitum on pellets and water. They were individually weighed and the testes were weighed before histological preparation.

The experimental animals were divided into 5 groups, each comprising 6 individuals as follows:

Group 1 - Control;

Group 2 - Plasmodium Infected animals (IP administration of $1 \times 10^{6} \mathrm{P}$. berghei ANKA);

Group 3 - Plasmodium Infected animals + Chloroquine $(5 \mathrm{mg} / \mathrm{kg}$ bodyweight)

Group 4 - Plasmodium Infected animals + Chloroquine $(10 \mathrm{mg} / \mathrm{kg}$ body weight)

Group 5 - Plasmodium Infected animals + Chloroquine $(15 \mathrm{mg} / \mathrm{kg}$ bodyweight)

The dose of Plasmodium berghei used in infecting the mice was 1 x106 P. berghei ANKA administered through intraperitonium in line with Makinde and Obih [13] methodology. Treatment of experimental animals commenced after 2 weeks of parasitaemia.

Group $3-5$ were treated for 7 days and sacrificed 24 hours after the last day of treatment. The groups were compared with the control (Group 1) and Plasmodium Infected animals (Group 2) controls. The mice from Group 1-5 were all kept under same condition and fed with water and feeds equally.

\section{Infection of Mice with Plasmodium berghei}

The parasite was obtained from the Nigerian Institute of Medical Research, Lagos, Nigeria. Each mouse was subsequently given standard intra-peritoneal inoculums of Plasmodium berghei parasites with the aid of $1 \mathrm{ml}$ disposable syringe. The malaria parasite, Plasmodium berghei, was maintained in mice by serial passaging from mouse to mouse all through the study.

\section{Determination Potency and Parasitaemia}

Blood samples were collected from the infected animals, thin blood smears were prepared, examined and parasitaemia calculated according to Ochei \& Kolhatka [14].

\section{Administration of the drug chloroquine}

Chloroquine diphosphate, 4 , aminoquinoline produced by sigma company, St. Louis Missouri, USA, was used for the study. A dose of $5 \mathrm{mg} / \mathrm{kg}$ was adequately prepared in line with first principle and administered to the laboratory animals accordingly.

\section{Histological Procedure}

Animals were sacrificed using the chloroform inhalation method, and the testes, were dissected out and weighed. Testicular tissues were adequately processed and stained with Haematoxylin and Eosin (H\&E) method according to Drury et al, [15]. The slides were examined microscopically with low power objective (X10) and photomicrographs were taken.

\section{RESULTS}

\section{General observations}

The fur of the mice was rough, food intake was reduced, there was lowered activeness, and their eyes were slightly pale whereas their tails were not.

\section{Histologic findings}

The examination of the histology of the testes revealed as seen in Fig. 1 that, size of the seminiferous tubule was observed, they are predominantly small with few large elongated seminiferous tubules, the large tubules were seen to contain more mature spermatids evidence by the number of flagella found in the lumen. The spermatogonia is present around the tubules. The Sertoli cells are very numerous and distributed around the tubules. The interstitial cells are generally unremarkable. Fig. 2 equally showed many larger and elongated seminiferous tubules (though may be affected by pattern of section) packed with lumen and spermatid as indicated by the presence of flagella. Sertoli cells are widely distributed at the edges of the tubules. The difference is spermatogenic activities does not seem to be remarkably different from that of the controls (Fig. 1). Also, section of testes in Fig. 3, shows large but congested seminiferous tubules most of which contains moderate number of spermatids.

The interstitial spaces are larger and seminiferous tubules are tightened. Section of the testes in Fig. 4, generally appears robust with active spermatogenesis and the relatively even distribution of small, medium and large seminiferous tubules all of which contain an appreciable amount of spermatid with the connective tissues between the tubules showing moderate distortion which are generally unremarkable. The general impression is one of a normal section. Section of testes as seen in Fig. 5 shows shrunken seminiferous tubules each with a fairly large lumen and relatively fewer spermatids. Interstitial spaces are large. 


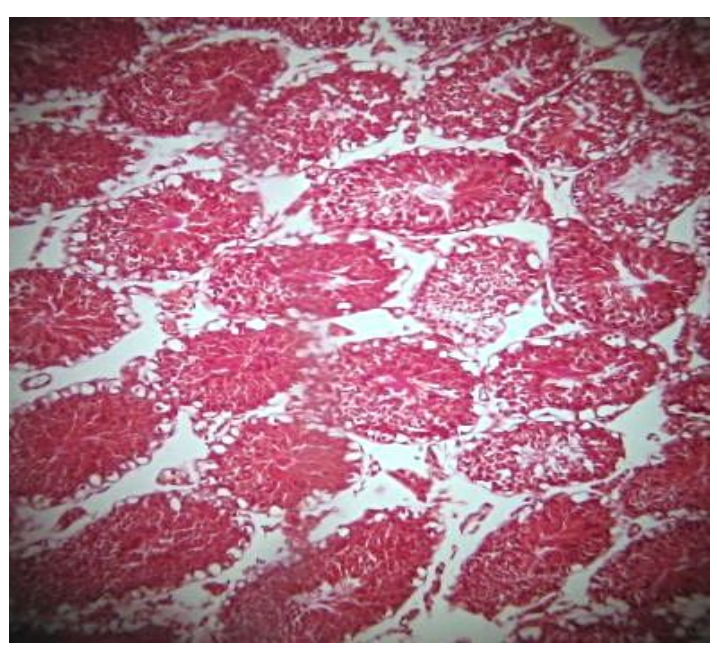

Fig. 1. A Photomicrograph of Testicular Section of Mouse in Control Group (H\&E, X40).

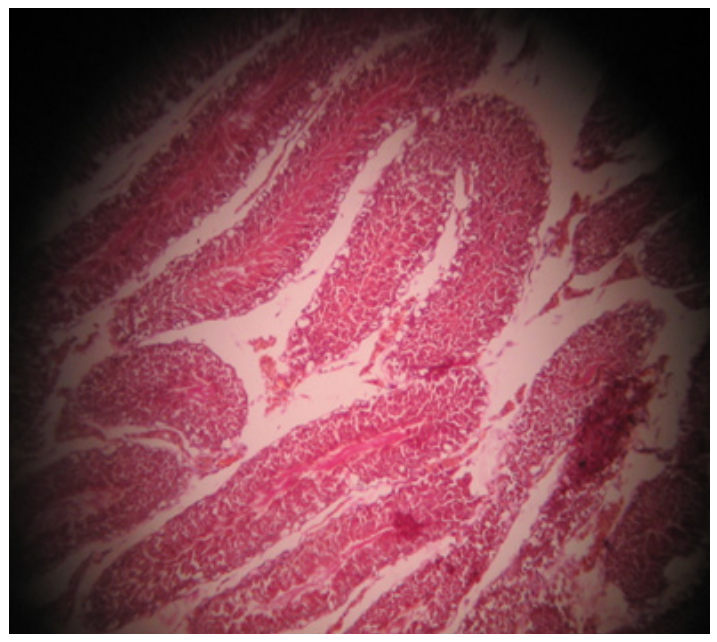

Fig. 2. A Photomicrograph of Testicular Section of Mouse for Plasmodium Infected animals (H\&E,X40).

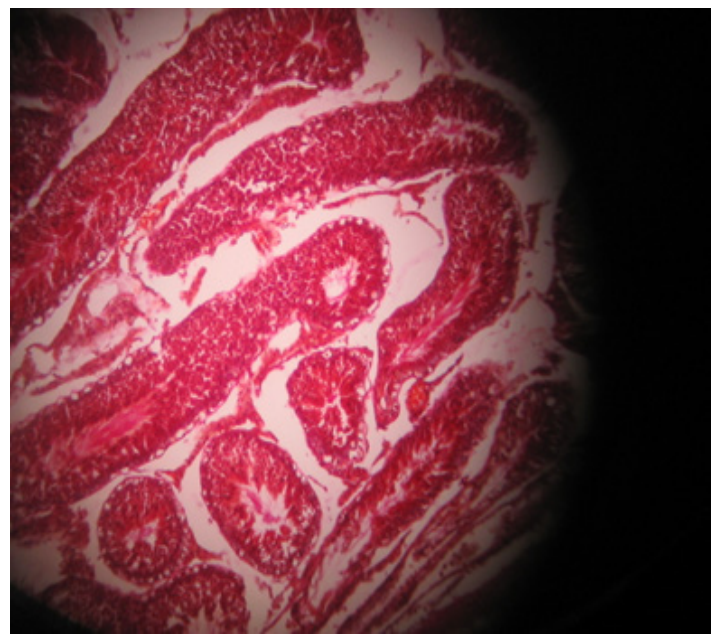

Fig. 3. A Photomicrograph of Testicular Section of Mouse for a Plasmodium Infected animal + Chloroquine $-5 \mathrm{mg} / \mathrm{kg}(\mathrm{H} \& \mathrm{E}, \mathrm{X} 40)$.

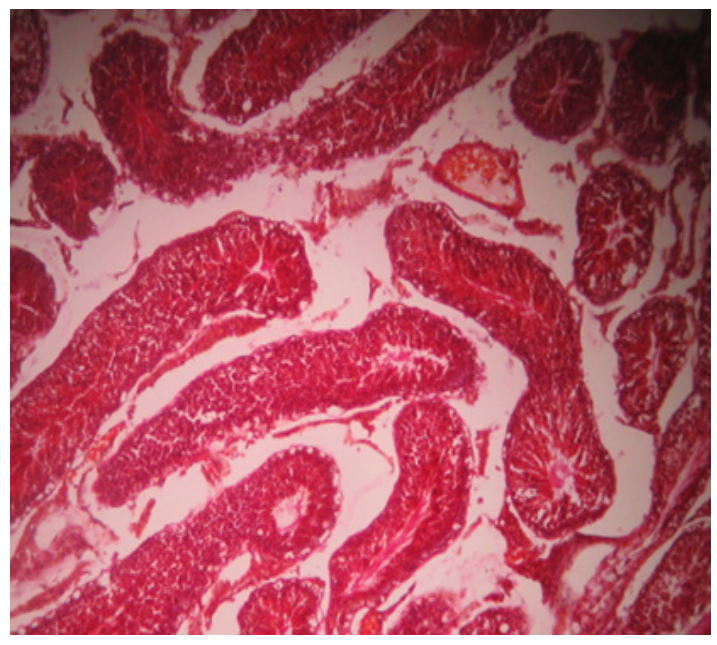

Fig. 4. A Photomicrograph of Testicular Section of Mouse for a Plasmodium Infected animal + Chloroquine $-10 \mathrm{mg} / \mathrm{kg}$ (H\&E. X40).

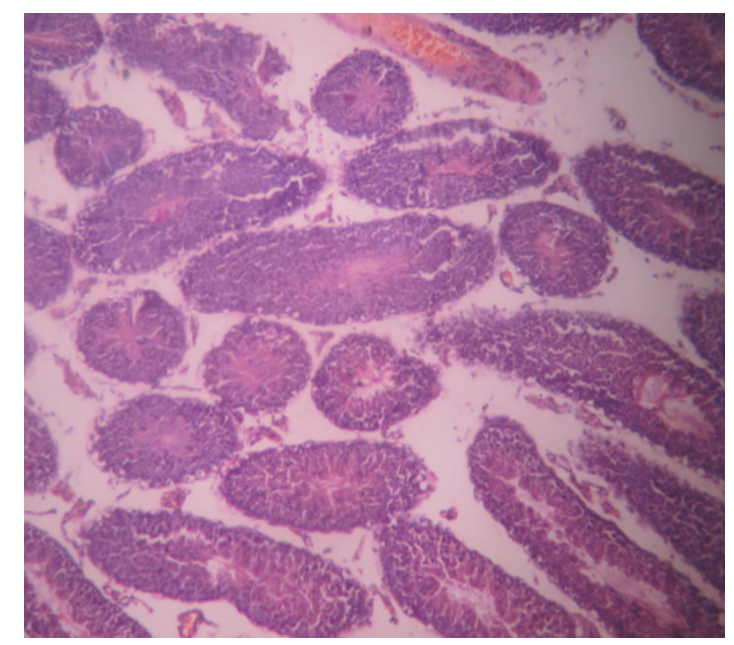

Fig. 5. A Photomicrograph of Testicular Section of Mouse for Plasmodium Infected animal + Chloroquine - $15 \mathrm{mg} / \mathrm{kg}$ (H\&E. X40)

There is degeneration in Sertoli cells, spermatocytes and spermatids. The connective tissue between the tubules is scanty so there is a general impression of lowered testicular activities. The different body weights of the mice used in various Groups 15 showed no difference in the testes weights as seen in Table 1 .

Table 1. Mice body and testes weights.

\begin{tabular}{lll}
\hline \multirow{2}{*}{$\begin{array}{l}\text { Swiss mice } \\
\text { groups }\end{array}$} & \multicolumn{2}{l}{ Mice body and testes weights } \\
\cline { 2 - 3 } & Body weight $(\mathrm{g})$ & Testes weight $(\mathrm{g})$ \\
\hline 1. & $20 \pm 5$ & $0.6 \pm 0.20$ \\
2. & $22 \pm 5$ & $0.6 \pm 0.20$ \\
3. & $24 \pm 5$ & $0.6 \pm 0.20$ \\
4. & $23 \pm 5$ & $0.6 \pm 0.20$ \\
5. & $25 \pm 5$ & $0.6 \pm 0.20$
\end{tabular}




\section{DISCUSSION}

The result of the study reveals mild to moderate changes in the testicular structures and insignificant testes weights. The use of chloroquine and related drugs like hydoxychloroquine for the treatment of malaria has been in existence for the long time. This study was carried out to ascertain the effect of chloroquine on the testes'morphology and weight of Swiss mice. The study may be limited by the fact that diet and cold weather of Jos may not be same with other places.

The photomicrograph of testicular section from Swiss mice infected with malaria when compared with the Control in Group 1 as in Fig. 1, shows a moderate distortion in some structures like seminiferous tubules, connective tissues between the tubules, lumen and interstitial spaces which may indicate effect in spermatogenic activities of mice. The cells of the tubules of Plasmodium Infected animal in Group 2 as in Fig. 2 tend to take up more stains than the ones among the Controls suggesting increased cellular activities. This shows that plasmodium berghei which caused parastaemia in mice could cause a little tissue effect on mice if not treated. The study agrees with Raji et al. [4] as they concluded that malaria parastaemia can inhibit fertility in male mice as a result of effects on the reproductive organ.

In comparing the photomicrograph of plasmodium Infected animal + chloroquine $5 \mathrm{mg} / \mathrm{kg}$ (the recommended dosage of chloroquine) (Fig. 3 representing Group 3) to the control (Fig. 1), showed some structural difference but the distortion is not significant. This could imply that malaria infection and adequate treatment with normal dose could have little effect on the testicular morphology especially with larger interstitial spaces and tightened seminiferous tubules. Such distortion could be normal after withdrawal of treatment just as Abolghasem et al [16] reported in their study that after withdrawal of chloroquine from mice, that the distortions were completely recovered.

However, the distortion and changes increased from the Group 4, plasmodium Infected animal + chloroquine - $10 \mathrm{mg} / \mathrm{kg}$ (Fig. 4), to Group 5, plasmodium infected animal + chloroquine - $15 \mathrm{mg} / \mathrm{kg}$ (Fig. 5) as noted from normal section to evidence of shrunken seminiferous tubules with a fairly large lumen, fewer spermatid, large interstitial spaces, degeneration in Sertoli cells, spermatocysts and spermatids. The scanty connective tissue between the tubules generally gives impression of lowered testicular activities. There is evidence of effect of higher dose of chloroquine treatment on testes morphology of mice. This study is therefore agreeing with Desai et al. [10]) that showed that chloroquine induced toxicity in dose dependent manner according to Ebong et al., [17]. This study also agrees with Asuquo et al. [9] that enlisted such distorted features of testes and graded the distortion along the dose increment.

From this study, Plasmodium berghei infection (malaria) and various doses of chloroquine administration did not affect the Swiss mice body weights and weight of the testes of Swiss mice (Table 1). Ekaluo et al. [10] and Asuquo et al. [9] reported that chloroquine reduced testes weights of male rats. It is possible that the disagreement from this study and others $[9,11]$ may be due to different environment and diet. However, Raji et al. [4] reported that malaria had no effect on the mice body weight and that of their testes. This study based on effect of chloroquine and Plasmodium berghei based on the distortion of testicular tissues agree with Asuquo et al. [18], Ebong et al., [17], Abolghasem et al [16], and Okalawon et al [19] and therefore, could affect the reproductive function of testes of mice as a result of chloroquine treatment. Similar result has also been observed with naphthoquinone in a recent study [20].

\section{CONCLUSION}

Plasmodium berghei affects Swiss mice testes morphology and therefore, very imperative to adequately treat malaria cases as it could affect male reproductive system. It is very important to avoid use of chloroquine in the treatment of malaria especially when the dose is above $5 \mathrm{mg} / \mathrm{kg}$ as it causes distortion and toxicity to the testes morphology. The study shows that small doses of chloroquine may not elicit much negative effects on the testes, but with graded increase in the doses of chloroquine spermatogenesis could be affected or disrupted with the end result on male fertility. The treatment of malaria with chloroquine or chloroquine related drugs could affect the male mice testes morphology and fertility.

\section{REFERENCES}

1. Uhlemann AC and Krishna S (2005). Antimalaria drug multi-drug resistance in Asia : Mechanisms and assessment. Curr .Top. Microbiol. Immunol.295:39-53

2. Plowe CV. (2005). Antimalarial drug resistance in Africa: strategies for monitoring and deterrence Curr. Top. Microbial Immune. 295:55-79.

3. Reis-Neto ET, Kakehasi AM, Pinheiro MM, Ferreira GA, LopesMarques CD, Henrique da Mota LM, Eduardo dos Santos Paiva ES, Pileggi GC, Sato EI, Gomides-Reis APM, Ricardo Machado Xavier RM, Provenza JR. Revisiting hydroxychloroquine and chloroquine for patients with chronic immunity-mediated inflammatory rheumatic diseases. Adv Rheumatol. 2020;60:30.

4. Raji Y, Akinsomisoye OS and Azeez MO. . Impact of the malaria parasite on reproductive indices of male mice. Reprod Med Biol ; 2006;5: 201-209.

5. Etukudoh NS, Opeyemi OO, Kunle-Alabi OT and Adeyombo FB . Naphthoquinone impairs reproductive functions in plasmodium berghei berghei-infected male swiss mice. Intl J Basic Appl Sci. 2019;8(1):1-4

6. Ashiru OA, Okanlawon AO and Noronha CC. Application of the points-sample intercepts of these mineferouse. tubles:evidence of decrease tubular size following chronic chloroquine administration. J Scan Microsc. 1991;15, 471-497.

7. Russel LD, Malone JP and Rapis SL. . Morphological pattern elicited by agents affecting spermatogenesis by distruption of its hormonal stimulation. Tissue cell. 1998;13:369-373

8. Asuquo OR, Igiri AO, Akpaso MI and Akpanabiatu MI. Histopathological and Biochemical Effects Of Chloroquine Phosphate On The Testes Of Male Albino Wistar Rats. Internet J Lab Med. 2009;4(2):10-17.

9. Desai KR, Patel PB, Siddiqui Z, Highland HN. . Subacute chloroquine toxicity on testis of Swiss albino mice and its amelioration by curcumin. Intl J Pharm Sci Res. 2018;12(12):32353246

10. Ekaluo UB, Udokpoh AE, Ikpeme EV, and Peter EU. . Effect of Chloroquine Treatments on Sperm Count and Weight of Testes in Male Rats. Global J Pure Appl Sci. 2008;14(2):175-177.

11. van der Spoel AC, Jeyakumar M, Butters TD, Charlton HM, Harry D. Moore HD, Dwek RA, and Platt FM . Reversible infertility in male mice after oral administration of alkylated imino sugars: A nonhormonal approach to male contraception. PNAS 2002;99(26):17173-17178.

12. Sengupta P. . The laboratory rat: Relating its age with human's. Int J Prev Med. 2013;4:624-30.

13. Makinde JM and Obih PO. . Screening of Morinda lucida leaf extract for antimalaria action on Plasmodium berghei berghei berghei in mice. Afr J Med Med Sci. 1985;14:59-63.

14. Ochei J. and Kalhatkah A. (2008). Introduction to Medical Laboratory Science, Theory and Practice: Tata McGraw-Hill publishing company limited. Page 111- 128

15. Drury RAB and Wallington EA. . Carleton's histological technique. Oxford University Press, Oxford New York Toronto, 1980;pp. 140-142.,496- 497 
16. Abolghasemi E, Moosa-Kazemi SH, Davoudi M, Reisi A, Satvat MT. Comparative study of chloroquine and quinine on malaria rodents and their effects on the mouse testis. Asian Pac J Trop Biomed. 2012;2(4):311-4.

17. Ebong PE, Eyong EU, Eleng MU and Ukwe, CN. Influence of chronic administration of chloquine on Leydig cell intergrity and testosterone profile of albino Wistar rats. Afr J Rep Health. 1999;3(2):97-107.

18. Asuquo OR, Igiri AO, Olawoyin OO, Eyong EU. Correlation of histological and histometric changes in rats testes treated with chloroquine phosphate. Niger J Physiol Sci. 2007;22(1-2):135-9.

19. Okanlawon AO, Ashiru OA. Sterological estimation of seminiferous tubular dysfunction in chloroquine treated rats. Afr $\mathrm{J}$ Med Med Sci. 1998;27(1-2):101-106

20. Etukudoh NS, Akindele OO, Kunle-Alabi OT, Bolarinwa AF Naphthoquinone impairs reproductive functions in plasmodium berghei berghei-infected male swiss mice. Int J Basic Appl Sci. $2019 ; 8(1): 1-4$ 